\title{
SECTION 3: PRELIMINARY ANALYSIS OF THE RESULTS
}

\subsection{INTRODUCTION}

In this section, we present the exploratory analysis of the results submitted by the extended deadline of December 2000. We first deal with Samples C-J, before considering the near-background samples A and B (Kauri wood). The aims of the exploratory analysis are to discover the range of results reported for each sample and the initial evaluation of the effects of any factors that might be a source of variation in the results. For each sample, in turn, we consider the main summary statistics - the number of results reported $(\mathrm{N})$, their mean or average, median, the standard deviation (StDev), the standard error of the mean (Sem), the quartiles (25th [Q1] and 75th [Q3] percentiles), and the minimum (Min) and maximum (Max) - before graphically studying the overall distribution of results in the form of a boxplot, with a view to identifying any extreme or outlying observations. The summary statistics and distribution of results for each laboratory type are also shown. Further details on the statistical methods used are contained in Appendix 3.

\subsection{FIRI SAMPLE C: TURBIDITE}

The sample was mainly coccolith calcite from a single distal turbidite emplaced on the Maderia Abyssal Plain. It was selected because of its provenance and age. Laboratories had been instructed not to pretreat the sample. This sample had also previously been used in TIRI.

Table 3.1 Descriptive statistics: all results (yr BP)

\begin{tabular}{lllllllll}
\hline $\mathrm{N}$ & Mean & Median & StDev & Sem & Min & Max & Q1 & Q3 \\
\hline 93 & 17,945 & 18,140 & 693 & 72 & 14,600 & 18,640 & 17,900 & 18,260 \\
\hline
\end{tabular}

Table 3.2 Descriptive statistics: all results (yr BP) by laboratory type

\begin{tabular}{lllllrllll}
\hline Type & N & Mean & Median & StDev & Sem & Min & Max & Q1 & Q3 \\
\hline AMS & 34 & 18,175 & 18,175 & 135 & 23 & 17,850 & 18,470 & 18,100 & 18,260 \\
GPC & 18 & 17,990 & 18,180 & 743 & 175 & 15,230 & 18,640 & 17,890 & 18,315 \\
LSC & 41 & 17,735 & 18,090 & 874 & 136 & 14,600 & 18,610 & 17,740 & 18,193 \\
\hline
\end{tabular}

FIRI sample C: turbidite: all results

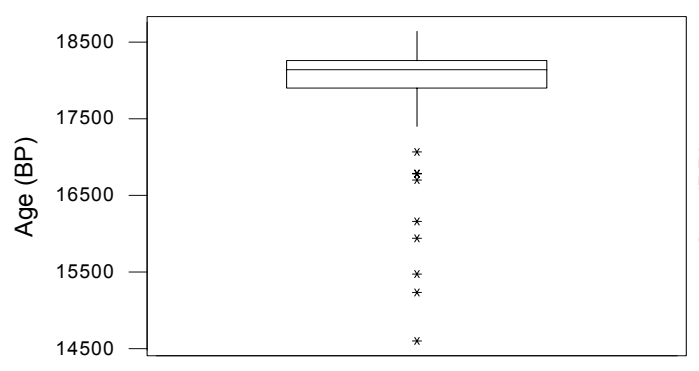

FIRI sample C: turbidite: all results by lab type

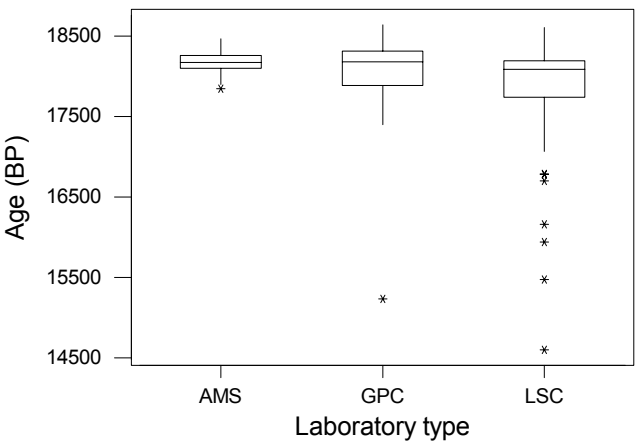

Figure 3.1 Distribution of results for Sample C by all results (left) and laboratory type (right) 


\subsubsection{Comments}

From Table 3.1, we can see that the mean and median age are slightly different at 17,945 and 18,140 $\mathrm{BP}$, suggesting that the distribution is skewed. There is a wide range of results $(14,600-8640 \mathrm{BP})$, but $50 \%$ of the values lie between 17,900 and 18,260 BP (interquartile range, Q3 to Q1, of $360 \mathrm{yr}$ ).

Table 3.2 shows the results for the different laboratory types. There is little difference in the median age for the 3 laboratory types, but, interestingly, we see that the standard deviation for both LSC and GPC laboratories are considerably larger than that for AMS laboratories.

Figure 3.1 graphically shows the distribution of results, with any extreme values (or outliers) identified by an asterisk.

We can see that there is a long lower tail for the turbidite results. When we consider the distribution by laboratory type, we see that this tail is predominantly composed of results from LSC laboratories.

In the homogeneity testing (Section 1), significant differences had been identified between the results from the 2 laboratories, which could be explained by the effect of pretreatment. The mean non-pretreated result had been 18,157 BP.

The turbidite sample had also been used in TIRI (see Part II), where on the basis of 30 results, calculation of the TIRI consensus value gave a result of $18,155 \mathrm{BP}$ with a $1 \sigma$ of $34 \mathrm{yr}$.

\subsection{FIRI SAMPLE D: BELFAST DENDRO-DATED PINE}

The sample was from a Scots pine tree from Garry Bog, Co. Antrim, Northern Ireland, and had 40 annual growth rings dating from 3239-3200 BC. This sample was distributed in duplicate as Samples D and F. Its ${ }^{14} \mathrm{C}$ age (from the master calibration curve) is approximately $4495 \mathrm{BP}$.

Table 3.3 Descriptive statistics: all results (yr BP)

\begin{tabular}{lllllllll}
\hline $\mathrm{N}$ & Mean & Median & StDev & Sem & Min & Max & Q1 & Q3 \\
\hline 108 & 4494.4 & 4517.5 & 224.2 & 21.6 & 2990.0 & 5060.0 & 4471.5 & 4579.0 \\
\hline
\end{tabular}

Table 3.4 Descriptive statistics: all results by laboratory type

\begin{tabular}{llllrrllll}
\hline Type & N & Mean & Median & StDev & \multicolumn{1}{c}{ Sem } & Min & Max & Q1 & Q3 \\
\hline AMS & 41 & 4530.3 & 4520.0 & 52.0 & 8.1 & 4430.0 & 4670.0 & 4500.0 & 4550.0 \\
GPC & 20 & 4495.1 & 4504.5 & 75.9 & 17.0 & 4273.0 & 4600.0 & 4468.5 & 4522.5 \\
LSC & 47 & 4462.9 & 4535.0 & 331.7 & 48.4 & 2990.0 & 5060.0 & 4400.0 & 4590.0 \\
\hline
\end{tabular}

FIRI sample D: Belfast wood: all results

FIRI sample D: Belfast wood: all results by lab type
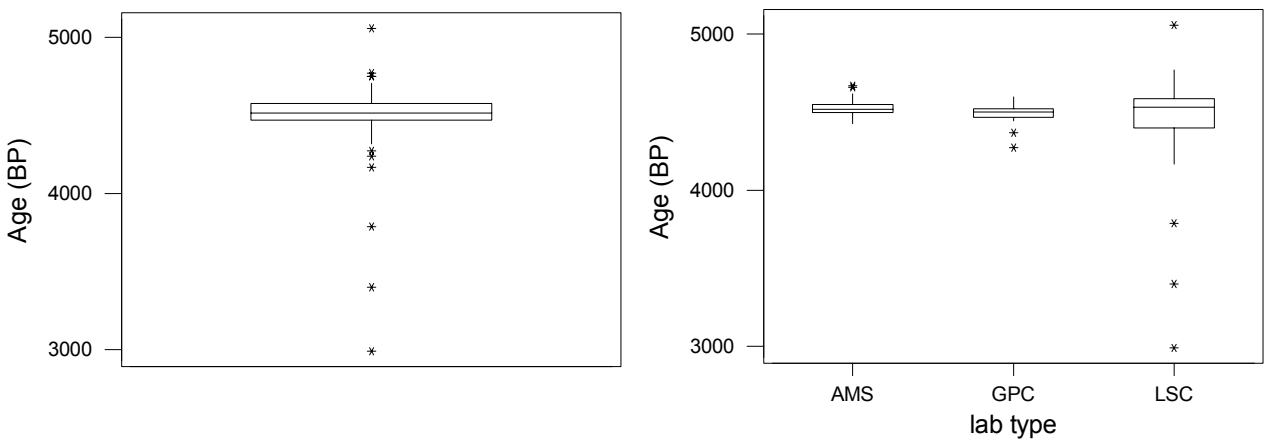

Figure 3.2 Distribution of results for Sample D by all results (left) and laboratory type (right) 


\subsubsection{Comments}

We can see from Table 3.3 that the mean and median age are slightly different at 4494 and 4517 BP. We see a wide range (2990-5060 yr), but 50\% of the values lie between 4471 and 4579 BP (i.e., just over $100 \mathrm{yr})$.

Table 3.4 shows the results for the different laboratory types. There is little difference in the median for the 3 laboratory types. Interestingly, as with Sample C, we see that the standard deviation for the results from the LSC laboratories is considerably larger than that for GPC and AMS laboratories.

From Figure 3.2, we can see that there is a lower tail for the results. When we consider the distribution by laboratory type, we see that this tail is predominantly composed of LSC results.

\subsection{FIRI SAMPLE F: BELFAST DENDRO-DATED PINE}

Table 3.5 Descriptive statistics: all results (yr BP)

\begin{tabular}{lllllllll}
\hline $\mathrm{N}$ & Mean & Median & StDev & Sem & Min & Max & Q1 & Q3 \\
\hline 103 & 4521.4 & 4504.0 & 195.8 & 19.3 & 4100.0 & 5870.0 & 4460.0 & 4560.0 \\
\hline
\end{tabular}

Table 3.6 Descriptive statistics: all results by laboratory type

\begin{tabular}{llllrlllll}
\hline Type & $\mathrm{N}$ & Mean & Median & StDev & Sem & Min & Max & Q1 & Q3 \\
\hline AMS & 37 & 4534.2 & 4534.0 & 62.0 & 10.2 & 4420.0 & 4710.0 & 4489.0 & 4570.0 \\
GPC & 21 & 4485.0 & 4470.0 & 120.1 & 26.2 & 4250.0 & 4740.0 & 4439.5 & 4528.5 \\
LSC & 45 & 4527.8 & 4500.0 & 279.9 & 41.7 & 4100.0 & 5870.0 & 4420.0 & 4555.0 \\
\hline
\end{tabular}

FIRI sample F: Belfast wood: all results

FIRI sample F: Belfast wood: all results by lab type
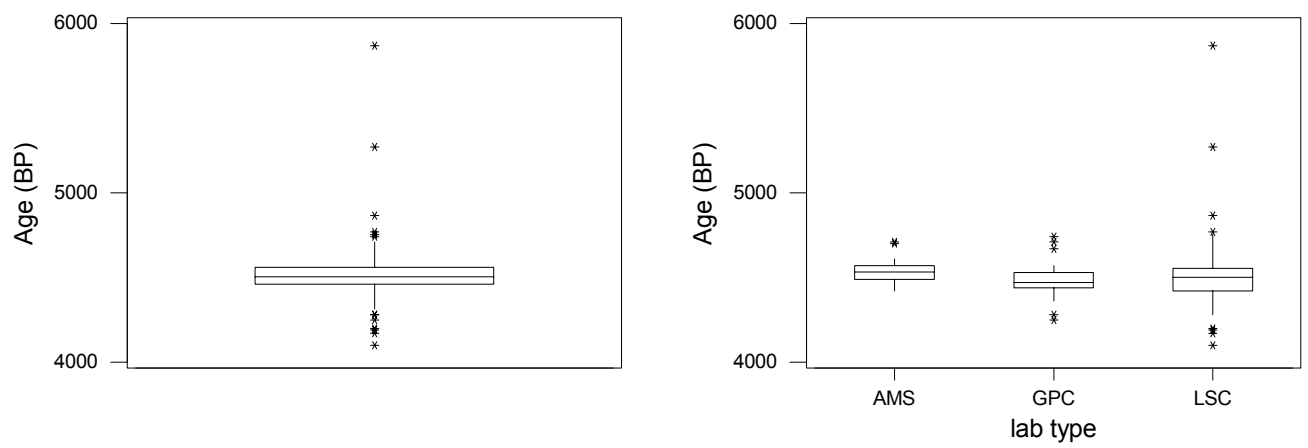

Figure 3.3 Distribution of results for Sample F by all results (left) and laboratory type (right)

\subsubsection{Comments}

From Table 3.5, we can see that the mean and median age are only slightly different at 4521 and 4504 BP. We also see a narrower range (4100-5870) than for Sample D and that $50 \%$ of the values lie between 4460 and 4560 BP (i.e., exactly $100 \mathrm{yr}$ ).

Table 3.6 shows the results for the different laboratory types. There is little difference in the median for the 3 laboratory types. Again, we see that the standard deviation for LSC laboratories is considerably larger than that for GPC and AMS.

The median and the middle 50\% range for Sample F is almost identical to the results for Sample D. 
From Figure 3.3, it is clear that there is both a lower and upper tail for the results. When we consider the distribution by laboratory type, we see that this tail is predominantly composed of results from LSC laboratories.

\subsection{FIRI SAMPLE E: HUMIC ACID}

Table 3.7 Descriptive statistics: all results (yr BP)

\begin{tabular}{lllllllll}
\hline $\mathrm{N}$ & Mean & Median & StDev & Sem & Min & Max & Q1 & Q3 \\
\hline 139 & 11,781 & 11,780 & 545 & 46 & 7700 & 15,150 & 11,670 & 11,872 \\
\hline
\end{tabular}

Table 3.8 Descriptive statistics: all results by laboratory type (yr BP)

\begin{tabular}{lllllrllll}
\hline Type & N & Mean & Median & StDev & \multicolumn{1}{c}{ Sem } & \multicolumn{1}{c}{ Min } & Max & Q1 & Q3 \\
\hline AMS & 65 & 11,822 & 11,800 & 188 & 23 & 11,430 & 13,000 & 11,765 & 11,870 \\
GPC & 26 & 11,768 & 11,734 & 240 & 47 & 11,300 & 12,314 & 11,617 & 11,920 \\
LSC & 48 & 11,731 & 11,726 & 888 & 128 & 7700 & 15,150 & 11,591 & 11,878 \\
\hline
\end{tabular}

FIRI sample E: humic acid: all results

FIRI sample E: humic acid: all results by lab type
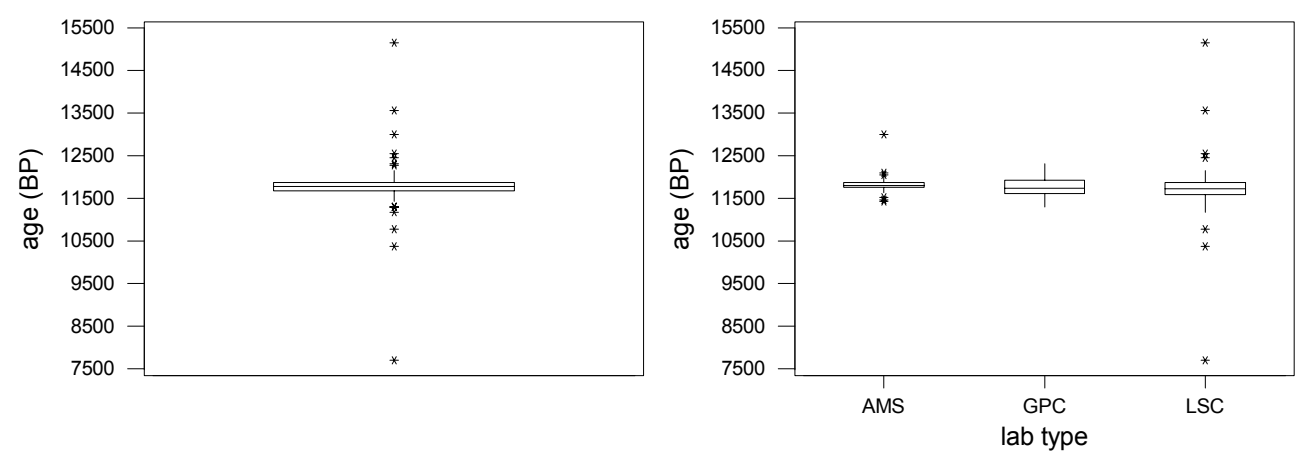

Figure 3.4 Distribution of results for Sample E by all results (left) and laboratory type (right)

\subsubsection{Comments}

For the humic acid, the mean and median are again in excellent agreement at 11,822 and 11,800 BP, respectively. Again, there is a wide range (7700-15,150 BP), but the interquartile range (IQR) is much narrower (11,670-11,872 BP). We see the same features (Figure 3.4) as before when we look at the summary statistics for each laboratory type with broadly similar mean/median values, but LSC laboratory results have a much larger standard deviation. The distribution of results shows the presence of some extreme values, again predominantly, but not exclusively, reported by LSC laboratories.

\subsection{FIRI SAMPLE G: BARLEY MASH}

This sample was provided as a duplicate sample with Sample J and reflected current atmospheric levels.

Table 3.9 Descriptive statistics: all results (pMC)

\begin{tabular}{lllllllll}
\hline $\mathrm{N}$ & Mean & Median & StDev & Sem & Min & Max & Q1 & Q3 \\
\hline 99 & 110.08 & 110.50 & 2.86 & 0.29 & 94.47 & 121.00 & 109.71 & 111.08 \\
\hline
\end{tabular}


Table 3.10 Descriptive statistics: all results by laboratory type (pMC)

\begin{tabular}{llllllllll}
\hline Type & $\mathrm{N}$ & Mean & Median & StDev & Sem & \multicolumn{1}{c}{ Min } & Max & Q1 & Q3 \\
\hline AMS & 34 & 110.3 & 110.3 & 0.68 & 0.12 & 109.0 & 111.9 & 109.8 & 110.8 \\
GPC & 19 & 110.6 & 111.0 & 1.36 & 0.31 & 107.0 & 112.6 & 110.0 & 111.4 \\
LSC & 46 & 109.6 & 110.4 & 4.04 & 0.60 & 94.2 & 121.0 & 108.8 & 111.3 \\
\hline
\end{tabular}

FIRI sample G: barley mash: all results FIRI sample G: barley mash: all results by lab type
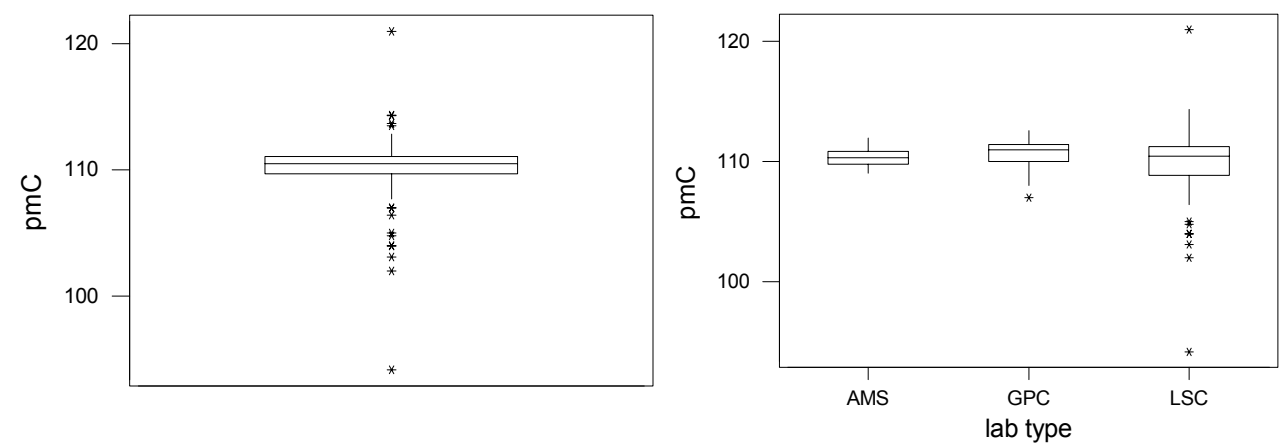

Figure 3.5 Distribution of results for Sample G by all results (left) and laboratory type (right)

\subsubsection{Comments}

The mean pMC value is estimated at 110.1 and $50 \%$ of the data lie in the range 109.7-111.1 (Table 3.9). It is clear, however, from the summary statistics and the graphs that again there are a number of extreme values and that these are reported predominantly by LSC laboratories (Table 3.10).

\subsection{FIRI SAMPLE J: BARLEY MASH}

Table 3.11 Descriptive statistics: all results (pMC)

\begin{tabular}{lllllllll}
\hline $\mathrm{N}$ & Mean & Median & StDev & Sem & Min & Max & Q1 & Q3 \\
\hline 99 & 110.4 & 110.6 & 2.73 & 0.27 & 97.1 & 122.0 & 110.0 & 111.3 \\
\hline
\end{tabular}

Table 3.12 Descriptive statistics: all results by laboratory type (pMC)

\begin{tabular}{llllllrlll}
\hline Type & N & Mean & Median & StDev & Sem & \multicolumn{1}{c}{ Min } & Max & Q1 & Q3 \\
\hline AMS & 99 & 110.4 & 110.6 & 2.73 & 0.27 & 97.1 & 122.0 & 110.0 & 111.3 \\
GPC & 19 & 110.8 & 110.7 & 1.19 & 0.27 & 108.3 & 114.4 & 110.4 & 111.3 \\
LSC & 45 & 110.0 & 110.8 & 3.93 & 0.59 & 97.1 & 122.0 & 109.0 & 111.6 \\
\hline
\end{tabular}

\subsubsection{Comments}

The mean pMC value is estimated at 110.4 and $50 \%$ of the data lie in the range 110.0-111.3. However, it is clear from the summary statistics and the graphs that again there are a number of substantial outliers and that these are reported by LSC laboratories. The distribution of results is very similar to that observed for FIRI G. 
FIRI sample J: barley mash: all results FIRI sample J: barley mash: all results by lab type
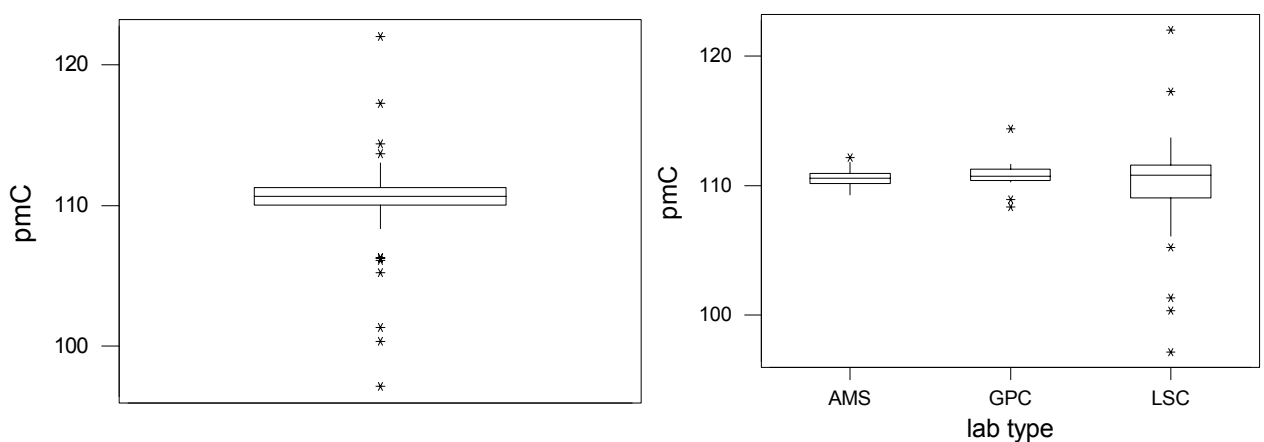

Figure 3.6 Distribution of results for Sample J by all results (left) and laboratory type (right)

\subsection{FIRI SAMPLE H: HOHENHEIM DENDRO-DATED OAK}

The sample had 20 annual growth rings dating from 313-294 BC, which corresponds to a ${ }^{14} \mathrm{C}$ age of $2215 \mathrm{BP}$.

Table 3.13 Descriptive statistics: all results (yr BP)

\begin{tabular}{lllllllll}
\hline N & Mean & Median & StDev & Sem & Min & Max & Q1 & Q3 \\
\hline 99 & 2240.9 & 2230.0 & 165.4 & 16.6 & 1530.0 & 2980.0 & 2180.0 & 2290.0 \\
\hline
\end{tabular}

Table 3.14 Descriptive statistics: all results by laboratory type (yr BP)

\begin{tabular}{llllrrllll}
\hline Type & N & Mean & Median & StDev & Sem & Min & Max & Q1 & Q3 \\
\hline AMS & 36 & 2228.7 & 2230.0 & 48.2 & 8.0 & 2135.0 & 2318.0 & 2202.3 & 2260.0 \\
GPC & 20 & 2259.7 & 2204.0 & 193.3 & 43.2 & 2093.0 & 2980.0 & 2180.0 & 2267.5 \\
LSC & 43 & 2242.4 & 2232.0 & 211.3 & 32.2 & 1530.0 & 2690.0 & 2160.0 & 2340.0 \\
\hline
\end{tabular}

FIRI sample H: German oak: all results

FIRI sample H: German oak: all results by lab type
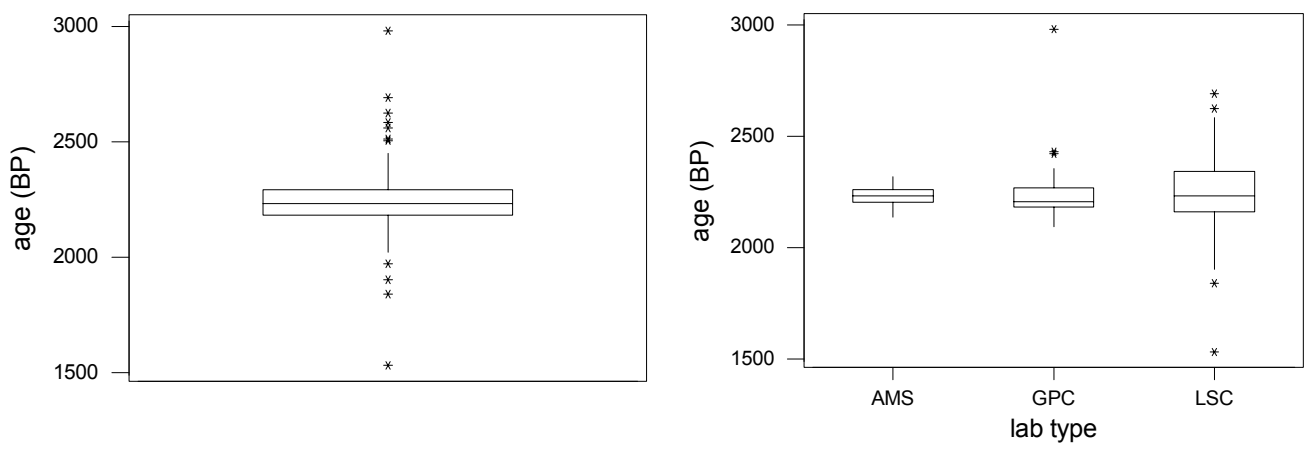

Figure 3.7 Distribution of results for Sample H by all results (left) and laboratory type (right)

\subsubsection{Comments}

The mean ${ }^{14} \mathrm{C}$ age is estimated as $2241 \mathrm{yr} \mathrm{BP}$ and the IQR is $2180-2290 \mathrm{BP}(90 \mathrm{yr}$ ), but the full range of the data is again extended due to the presence of outliers. The mean and the median age correspond well to the master calibration value ascribed to this sample. 


\subsection{FIRI SAMPLE I: BELFAST CELLULOSE}

Table 3.15 Descriptive statistics: all results (yr BP)

\begin{tabular}{|c|c|c|c|c|c|c|c|c|}
\hline $\mathrm{N}$ & Mean & Median & StDev & Sem & Min & Max & Q1 & Q3 \\
\hline 96 & 4484.6 & 4490.0 & 218.8 & 22.3 & 3780.0 & 5650.0 & 4420.0 & 4560.0 \\
\hline
\end{tabular}

Table 3.16 Descriptive statistics: all results by laboratory type (yr BP)

\begin{tabular}{llllrlllll}
\hline Type & N & Mean & Median & StDev & Sem & Min & Max & Q1 & Q3 \\
\hline AMS & 35 & 4499.1 & 4490.0 & 74.1 & 12.5 & 4400.0 & 4710.0 & 4450.0 & 4550.0 \\
GPC & 18 & 4498.8 & 4463.0 & 192.4 & 45.3 & 4290.0 & 5100.0 & 4399.0 & 4493.8 \\
LSC & 43 & 4466.9 & 4500.0 & 297.2 & 45.3 & 3780.0 & 5650.0 & 4380.0 & 4580.0 \\
\hline
\end{tabular}

FIRI sample I: Belfast cellulose, all results FIRI sample I: Belfast cellulose, all results by lab type
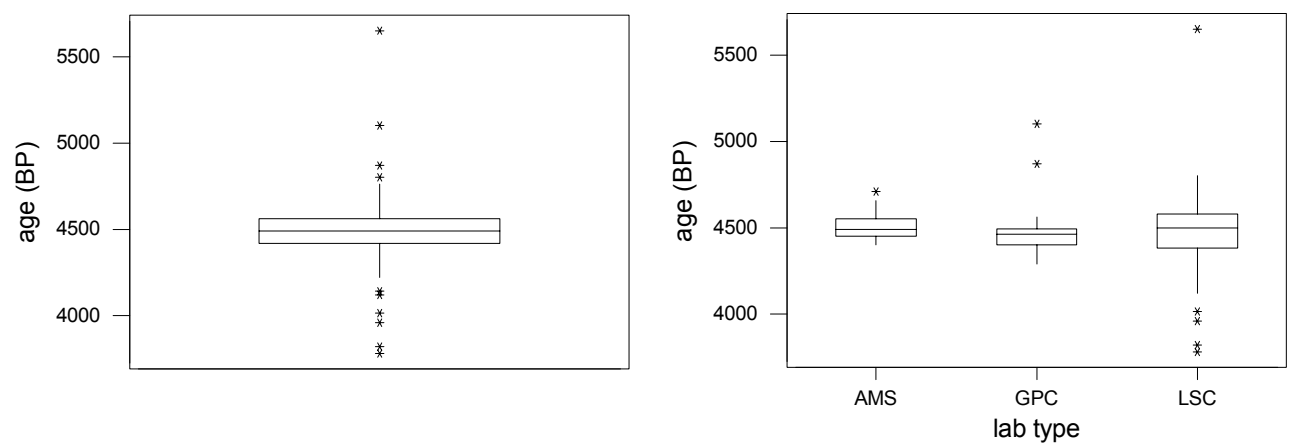

Figure 3.8 Distribution of results for Sample I by all results (left) and laboratory type (right)

The second Belfast sample spanned a contiguous set of rings to FIRI D and F. The sample, which had a finite 40-yr ring span, had a dendrochronologically-determined age span of 3299-3257 BC. This corresponds roughly to a ${ }^{14} \mathrm{C}$ age of $4471 \mathrm{BP}$.

\subsubsection{Comments}

The mean and median are very close together at $4485 \mathrm{yr} \mathrm{BP}$, and approximately $15 \mathrm{yr}$ younger than linked samples D and F. The IQR is 140 yr. The graphs show the presence of outliers, again predominantly from LSC laboratories.

\subsection{CONCLUSIONS FROM THE PRELIMINARY DISTRIBUTION OF RESULTS}

The preliminary analysis of the results for FIRI Samples C-J has shown a consistent pattern, with a reasonably tight IQR (the mid-50\% of the results) but with a large range (usually determined by a small number of extreme values). The IQR is reasonably constant at around $100 \mathrm{yr}$, extending to 300 yr for the oldest sample (Sample C). In the main, although not solely, the extreme results have been reported by liquid scintillation laboratories. From the tables of summary statistics, it is also apparent that the standard deviation in all samples is much larger for LSC laboratories than for GPC or AMS laboratories. Figures A1.a to A1.j in Appendix 1 show the full distribution of results for each sample as well as the $\pm 2 \sigma$ range for the individual results. These figures also show the same overall pattern as observed in the boxplots, but now the effect of, and relationship to, the quoted error is also 
apparent. In these figures, a steeply sloping section indicates that there are a large number of laboratories with very similar results; such a feature is very striking in Figure A1.e, and to a lesser extent in A1.d and A1.f. It is also clear that the size of the quoted error does vary quite substantially amongst laboratories. This preliminary analysis has not formally used the associated laboratory quoted error and in the next section, the quoted errors are further explored. For this purpose, all results in Section 3.11 have been quoted in \% modern carbon (pMC) for comparability purposes.

\subsection{SUMMARY OF THE DISTRIBUTION OF QUOTED ERRORS}

\section{Boxplots of pMCsigma values for each sample}

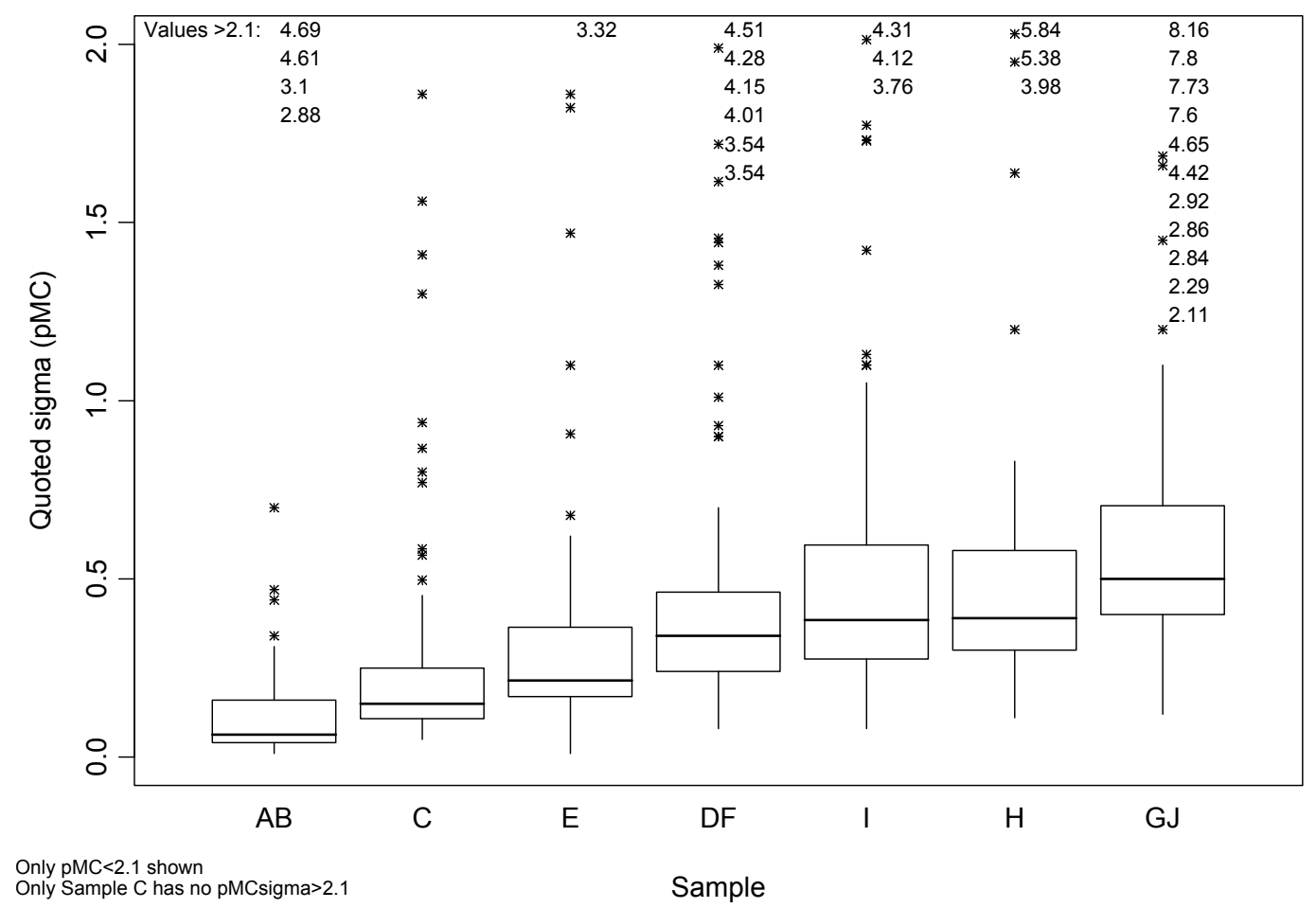

Figure 3.9 Distribution of laboratory quoted errors

Figure 3.9 shows the distribution of quoted errors (all results are given in terms of pMC) for all samples (now including Samples A and B). Extreme values (outliers) are clearly marked by the asterisks. It is clear from the figure that there is a relationship between the pMC and the quoted error, with the quoted error slowly increasing as the sample pMC increases. Similarly, from figures for the different laboratory types, it was quite clear that the quoted errors tend to be larger and more variable for LSC laboratories than for the other laboratory types, and that the AMS laboratories quoted errors tend to be smaller and for there to be much less scatter in their magnitude.

\subsection{SUMMARY OF THE $\delta^{13} \mathrm{C}$}

Laboratories were asked to provide $\delta^{13} \mathrm{C}$ values for each sample and to indicate whether these values were measured or estimated. Table 3.17 summarizes the number of laboratories providing this information. In the reporting questionnaire, laboratories were also asked to indicate the stage of the dating process to which the fractionation measure best referred. 
Table 3.17 Summary of $\delta^{13} \mathrm{C}$ reporting

\begin{tabular}{llllll}
\hline Lab type & Estimated & Estimated and measured & Measured & Missing & Total nr of labs \\
\hline AMS & 0 & 2 & 22 & 1 & $\mathbf{2 5}$ \\
GPC & 2 & 1 & 14 & 11 & $\mathbf{2 8}$ \\
LSC & 8 & 2 & 29 & 10 & $\mathbf{4 9}$ \\
All & 10 & 5 & 65 & 12 & $\mathbf{9 2}$ \\
\hline
\end{tabular}

The different parts of the process where $\delta^{13} \mathrm{C}$ was measured were classified as:

1. The raw material;

2. The material after pretreatment;

3. The actual sample measured.

The $\delta^{13} \mathrm{C}$ values for each sample are summarized first for all results in Table 3.18, and then by the stage of the process in Table 3.19.

Table 3.18 Summary table for $\delta^{13} \mathrm{C}$ (all results)

\begin{tabular}{lrlllllll}
\hline Sample & \multicolumn{1}{c}{$\mathrm{N}$} & Mean & Median & StDev & Min & Max & Q1 & Q3 \\
\hline AB & 170 & -23.9 & -24 & 1.48 & -31 & -20.1 & -24.7 & -23.3 \\
C & 82 & 0.51 & 1.1 & 2.84 & -22.6 & 3.864 & 0.8 & 1.2 \\
DF & 188 & -24.8 & -25.0 & 1.36 & -32.2 & -21.6 & -25.3 & -24 \\
E & 119 & -28.7 & -29.1 & 2.2 & -34.3 & -12.3 & -29.5 & -28.4 \\
GJ & 172 & -28.9 & -29.1 & 1.34 & -34.1 & -24.5 & -29.5 & -28.6 \\
H & 87 & -25.0 & -24.9 & 1.34 & -31.1 & -21.1 & -25.5 & -24.4 \\
I & 86 & -23.8 & -23.7 & 0.85 & -25.5 & -20 & -24.3 & -23.4 \\
\hline
\end{tabular}

Table 3.19 Summary statistics for $\delta^{13} \mathrm{C}$ by process stage

\begin{tabular}{|c|c|c|c|c|c|c|c|c|c|c|c|c|}
\hline Sample/ & $\mathbf{A B}$ & (1) & (2) & (3) & C & (1) & (2) & (3) & DF & (1) & (2) & (3) \\
\hline $\mathrm{N}$ & 153 & 10 & 62 & 66 & 72 & 12 & 22 & 20 & 165 & 9 & 70 & 68 \\
\hline Mean & -23.8 & -24.2 & -23.7 & -23.9 & 0.6 & 0.9 & 0.9 & 1.0 & 4.7 & -25.1 & -24.5 & -25.0 \\
\hline Median & -23.9 & -24.1 & -23.8 & -23.9 & 1.1 & 1.0 & 1.1 & 1.1 & 24.9 & -25.0 & -24.3 & -25.0 \\
\hline StDev & 1.5 & 0.5 & 1.4 & 1.8 & 3.0 & 0.5 & 0.8 & 1.3 & 1.4 & 0.6 & 1.3 & 1.6 \\
\hline Min & -31.0 & -25.0 & -31.0 & -31.0 & -22.6 & -0.7 & -2.4 & -3.4 & -32.2 & -26.0 & -32.2 & -32.2 \\
\hline Q1 & -24.4 & -24.5 & -24.2 & -24.6 & 0.9 & 0.8 & 0.9 & 1.0 & & -25.5 & -25.1 & -25.5 \\
\hline Q3 & -23.2 & -24.0 & -23.2 & -22.9 & 1.3 & 1.2 & 1.1 & 1.4 & .9 & -25.0 & -23.7 & -24.1 \\
\hline Max & -20.1 & -23.4 & -20.9 & -20.1 & 3.9 & 1.3 & 1.6 & 3.9 & 1.6 & -24.0 & -21.7 & -21.6 \\
\hline Sample/( & $\mathbf{E}$ & (1) & (2) & (3) & GJ & (1) & (2) & (3) & H & (1) & (2) & (3) \\
\hline $\mathrm{N}$ & 69 & 20 & 17 & 27 & 155 & 37 & 37 & 67 & 79 & 4 & 34 & 34 \\
\hline $\mathrm{Mec}$ & -29.0 & -28.8 & -29.1 & -29.3 & -29.1 & -28.8 & -29.0 & -29.4 & -25.0 & -25.4 & -24.7 & -25.2 \\
\hline Med & -29.1 & -28.8 & -29.1 & -29.3 & -29.1 & -29.0 & -28.9 & -29.3 & -24.8 & -25.3 & -24.8 & -25.0 \\
\hline StD & 1.3 & 1.5 & 1.1 & 0.6 & 0.9 & 0.9 & 0.6 & 1.1 & 1.4 & 0.6 & 1.5 & 1.4 \\
\hline Min & -32.9 & -29.9 & -32.9 & -30.2 & -34.1 & -29.8 & -30.8 & -34.1 & -31.1 & -26.0 & -31.1 & -31.1 \\
\hline Q1 & -29.5 & -29.5 & -29.2 & -29.6 & -29.5 & -29.5 & -29.2 & -29.7 & -25.5 & -25.9 & -25.2 & -25.5 \\
\hline Q3 & -28.8 & -28.8 & -28.9 & -29.1 & -28.7 & -28.6 & -28.5 & -28.9 & -24.3 & -24.8 & -24.1 & -24.4 \\
\hline Max & -23.0 & -23.2 & -27.7 & -27.6 & -25.9 & -26.0 & -28.0 & -25.9 & -21.1 & -24.8 & -21.1 & -23.0 \\
\hline Samp & I & (1) & (2) & (3) & & & & & & & & \\
\hline$N$ & 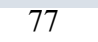 & & 2 & & & & & & & & & \\
\hline & & -23.7 & -23.5 & -2 & & & & & & & & \\
\hline & -23.7 & -23.7 & -23.5 & -23 & & & & & & & & \\
\hline StDev & 0 & 0.6 & 0.6 & & & & & & & & & \\
\hline Min & -25.5 & -25.1 & -25.0 & -25 & & & & & & & & \\
\hline Q1 & -24.0 & -24.0 & -23.7 & -2 & & & & & & & & \\
\hline Q3 & -23.4 & -23.2 & -23.3 & -23.6 & & & & & & & & \\
\hline Max & -21.7 & -22.3 & -21.7 & -21.7 & & & & & & & & \\
\hline
\end{tabular}


The boxplots in Figure 3.10 show the pattern of measured $\delta^{13} \mathrm{C}$ values for the samples, except Sample C. The barley and humic samples are comparable and lighter than the wood samples. There may be some suggestion that Sample I (cellulose) is heavier than Samples D and F. It is also of interest to consider the differences in the $\delta^{13} \mathrm{C}$ values at the different stages and this is shown graphically in Figures 3.11 and 3.12. It should be remembered that the $\delta^{13} \mathrm{C}$ values should not be used as the reference isotopic ratio for these samples; rather, it may prove a useful marker for the variation in measurement. The results have shown small differences in the different process stages. There is little evidence for any of the samples that there is significant variation in the fractionation incurred at the different stages. There is some variation in the $\delta^{13} \mathrm{C}$ values quoted, but these effects are likely to be small in the overall variation of the results.

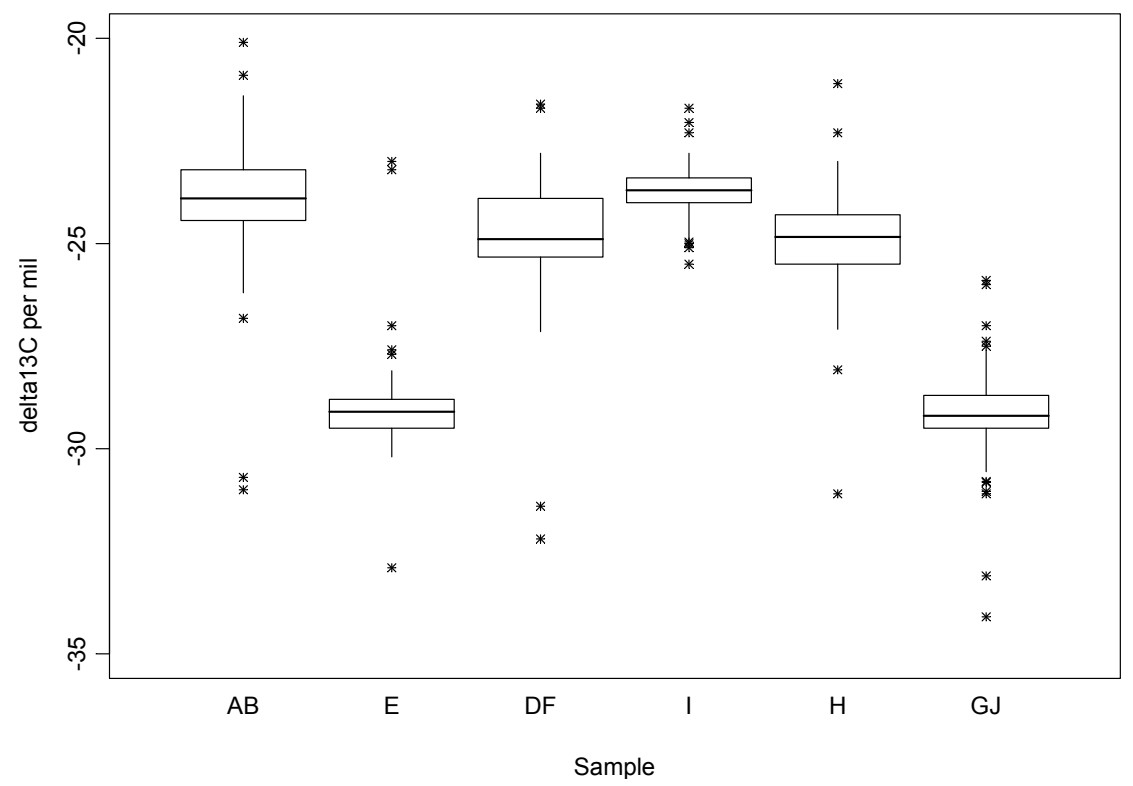

Figure $3.10 \delta^{13} \mathrm{C}$ for all samples (except Sample C, turbidite)

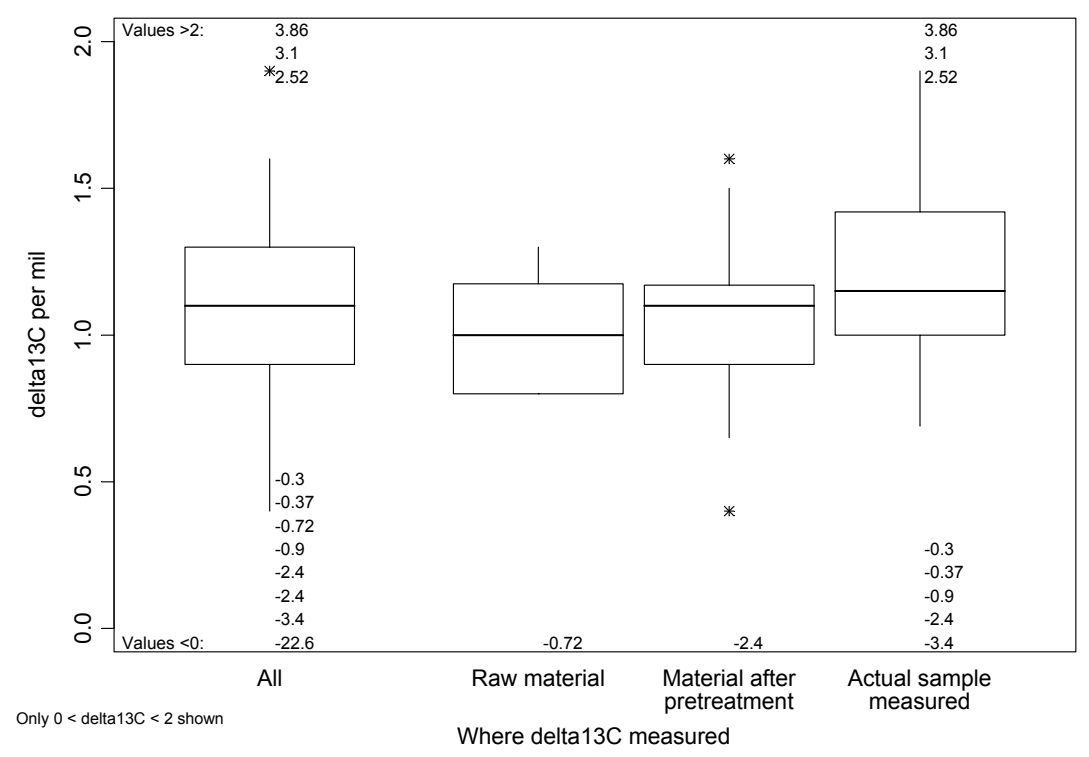

Figure $3.11 \delta^{13} \mathrm{C}$ for Sample C (turbidite) in process for different point of measure categories 


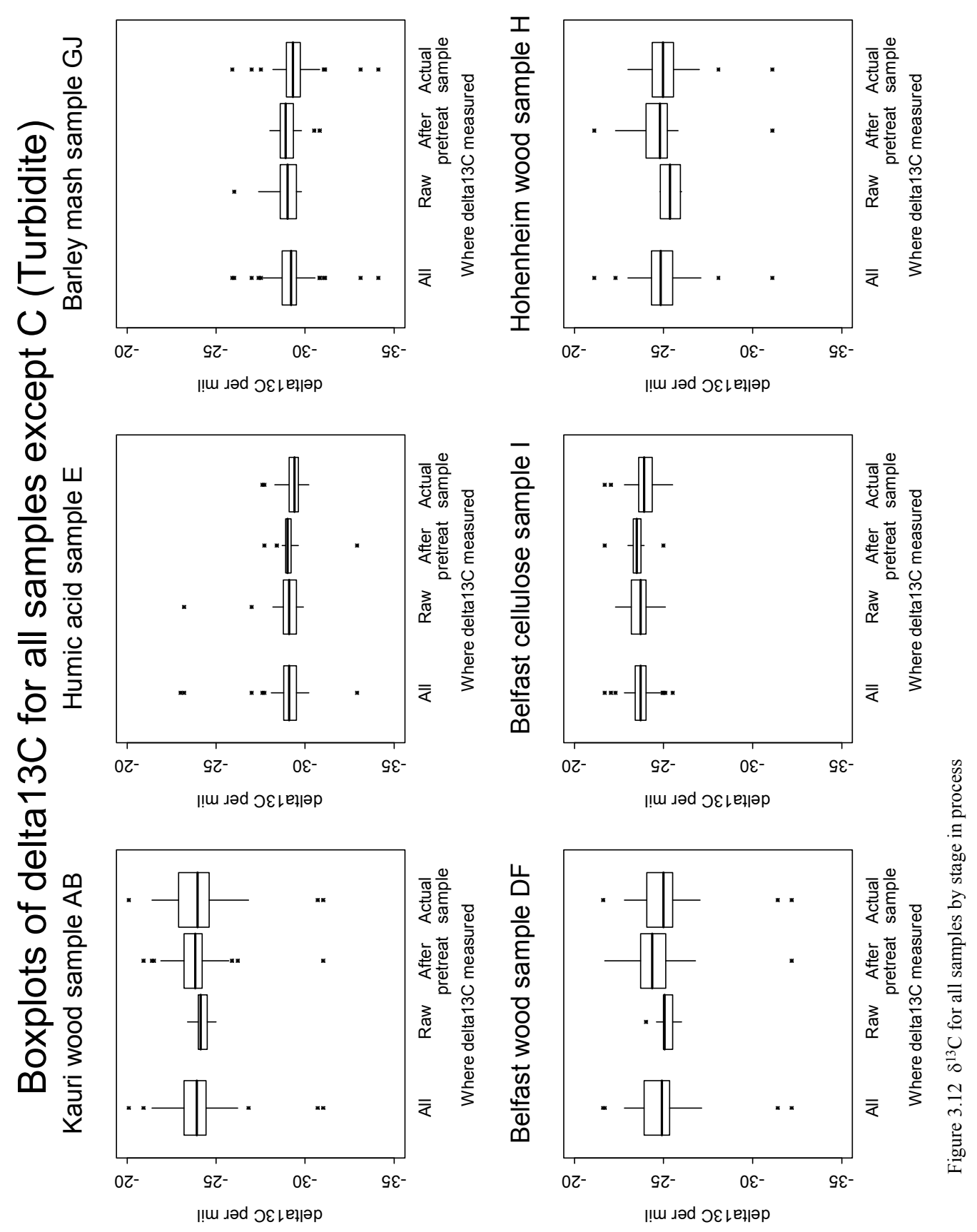




\subsection{OUTLIERS OR EXTREME VALUES}

\subsubsection{Outlier Definitions}

There are many ways for defining outliers and no universal statistical definition. In this report, we have used a conventional definition that is widely used in the statistical software, and in particular, is used to identify outliers when producing boxplots.

For the purposes of this investigation of outliers and the similarities they exhibited, outliers were defined as all results greater or less than $1.5 \times \mathrm{IQR}$ from the middle $50 \%$ of the results or result $<\mathrm{Q} 1$ $-1.5(\mathrm{Q} 1-\mathrm{Q} 3)$ or result $>\mathrm{QU}+1.5(\mathrm{QL}-\mathrm{QU})$, where $Q L$ and $Q U$ are the upper and lower quartiles, respectively.

In a previous analysis of ${ }^{14} \mathrm{C}$ results from an intercomparison, the standard consensus (Rozanski et al. 1992) calculations were used at the first stage of the calculation, a definition such that outliers were classed as those results that were more than $3 \mathrm{IQR}$ from the middle $50 \%$ of the results (i.e., result $<\mathrm{QL}-3(\mathrm{QL}-\mathrm{QU})$ or result $>\mathrm{QU}+3(\mathrm{QL}-\mathrm{QU})$, where $Q L$ and $Q U$ are the upper and lower quartiles, respectively.

Using the 1.5 IQR definition, the outlier boundaries are defined below:

Table 3.20 Outlier boundaries (in pMC for Samples AB and GJ)

\begin{tabular}{llllllll}
\hline Limit & $\mathrm{AB}$ & $\mathrm{C}$ & $\mathrm{DF}$ & $\mathrm{E}$ & $\mathrm{GJ}$ & $\mathrm{H}$ & $\mathrm{I}$ \\
\hline Lower & -0.5 & 17,362 & 4313 & 11,358 & 108 & 2004 & 4210 \\
Upper & 1.3 & 18,796 & 4723 & 12,168 & 113 & 2457 & 4770 \\
\hline
\end{tabular}

\subsubsection{Outlier Description}

A total of 122 observations from 1056 (i.e., slightly over 10\%) were identified as outliers using these definitions and here we explore the nature of these outlier observations.

Table 3.21 Percentage distribution of outliers amongst laboratory types

\begin{tabular}{lcr}
\hline Laboratory type & Number of identified outliers & \multicolumn{1}{c}{$\%$} \\
\hline AMS & 1 & 0.82 \\
GPC & 15 & 12.30 \\
LSC & 106 & 86.89 \\
All & $\mathbf{1 2 2}$ & $\mathbf{1 0 0 . 0 0}$ \\
\hline
\end{tabular}

Thus, of the 122 outliers, $87 \%$ came from LSC laboratories.

We can also consider whether there was any association with the outlier results and the modern standard material or background material used.

Table 3.22 Number of outliers reported where laboratory used the given standard material

\begin{tabular}{lll}
\hline Modern standard material & Number of outliers & $\%$ \\
\hline ASUC & 15 & 14.02 \\
Benz & 17 & 15.89 \\
NBS1 & 23 & 21.50 \\
NBS2 & 45 & 42.06 \\
other & 7 & 6.54 \\
\hline
\end{tabular}


Over half of the outliers were submitted by laboratories using NBS Ox1 and NBS Ox2.

Table 3.23 Number of outliers reported where laboratory used the given background material

\begin{tabular}{lcr}
\hline Background material & Number of outliers & $\%$ \\
\hline Anth & 17 & 17.17 \\
Benz & 39 & 39.39 \\
Coal & 5 & 5.05 \\
Graph & 4 & 4.04 \\
Marble & 17 & 17.17 \\
None & 2 & 2.02 \\
Other & 15 & 15.15 \\
All & $\mathbf{9 9}$ & $\mathbf{1 0 0 . 0 0}$ \\
\hline
\end{tabular}

The distribution of outliers is uniform over the sample; thus, no single sample contributes the majority of the outliers if we consider the joint distribution of laboratory type and standard used for those outlier results. The distribution is shown in the table below.

In terms of background material, the most common background material is benzene (scintillationgrade benzene) and over $39 \%$ of the outliers are associated with the use of benzene as the background material.

Table 3.24 Number of outliers reported where laboratory used the given background material

\begin{tabular}{llr}
\hline Sample & Number of outliers & $\%$ \\
\hline A & 11 & 9.02 \\
B & 7 & 5.74 \\
C & 11 & 9.02 \\
D & 12 & 9.84 \\
E & 13 & 10.66 \\
F & 16 & 13.11 \\
G & 16 & 13.11 \\
H & 13 & 10.66 \\
I & 13 & 10.66 \\
J & 10 & 8.20 \\
\hline
\end{tabular}

Table 3.25 Numbers of outliers for given laboratory type and modern standard material

\begin{tabular}{lcccclr}
\hline & ASUC & Benz & NBS1 & NBS2 & Other & All \\
\hline AMS & 0 & 0 & 0 & 1 & 0 & $\mathbf{1}$ \\
GPC & 2 & 0 & 2 & 11 & 0 & $\mathbf{1 5}$ \\
LSC & 13 & 17 & 21 & 33 & 7 & $\mathbf{9 1}$ \\
All & $\mathbf{1 5}$ & $\mathbf{1 7}$ & $\mathbf{2 3}$ & $\mathbf{4 5}$ & $\mathbf{7}$ & $\mathbf{1 0 7}$ \\
\hline
\end{tabular}

There appears to be no statistical association between laboratory type and modern standard used for the outlier results.

Table 3.26 Numbers of outliers for given laboratory type and background material

\begin{tabular}{lccllccc}
\hline & Anth & Benz & Coal & Graph & Marble & Other & All \\
\hline AMS & 0 & 0 & 1 & 0 & 0 & 0 & $\mathbf{1}$ \\
GPC & 4 & 0 & 4 & 4 & 1 & 2 & $\mathbf{1 5}$ \\
LSC & 13 & 39 & 0 & 0 & 16 & 15 & $\mathbf{8 3}$ \\
All & $\mathbf{1 7}$ & $\mathbf{3 9}$ & $\mathbf{5}$ & $\mathbf{4}$ & $\mathbf{1 7}$ & $\mathbf{1 7}$ & $\mathbf{9 9}$ \\
\hline
\end{tabular}


It seems that there is a statistical association between laboratory type, background material, and outlier results.

\subsubsection{Distribution of Outliers Across Labs}

Of the 92 laboratories in the intercomparison, there were 39 (42\%) which had at least 1 result classed as an outlier. Information about each of these is given in the following tables.

Of the 39 laboratories that had 1 or more outliers, almost $60 \%$ (23) of these had more than 1 of their results thus classed and over one-fifth (9) had 5 or more such results (see Table 3.27).

Table 3.27 Count of laboratories in different number-of-outlier-results groups

\begin{tabular}{llllllllllll}
\hline Number of outliers & 0 & 1 & 2 & 3 & 4 & 5 & 6 & 7 & 9 & 11 & Total \\
\hline Number of laboratories & 53 & 16 & 6 & 4 & 4 & 1 & 3 & 2 & 2 & 1 & $\mathbf{9 2}$ \\
\hline
\end{tabular}

From Table 3.28, over 75\% (30) of the laboratories with outliers used LSC, while all but one of the rest used GPC. Thus, a larger proportion of the outlier laboratories used LSC, compared to the LSC representation in the overall set of results, where $53 \%$ of the laboratories used LSC.

Table 3.28 Count of laboratories in different measurement method groups

\begin{tabular}{lccll}
\hline Measurement method & AMS & GPC & LSC & Total \\
\hline Number of outlier laboratories & 1 & 8 & 30 & $\mathbf{3 9}$ \\
All laboratories & 25 & 18 & 49 & $\mathbf{9 2}$ \\
\hline
\end{tabular}

From Table 3.29, we can see that just over 50\% (20) of these 39 laboratories did not state that they measured the $\delta^{13} \mathrm{C}$ for all their samples. Nine of these 20 laboratories definitely estimated $\delta^{13} \mathrm{C}, 3$ used both measured and estimated values, while the other 8 did not specifying whether or not they did. In the overall case, only $29 \%$ (27) of the 92 did not state that they measured the $\delta^{13} \mathrm{C}$ for all their samples.

Table 3.29 Counts of outlier and all laboratories' $\delta^{13} \mathrm{C}$ categories

\begin{tabular}{lcllcl}
\hline & & Estimated and & & & \\
$\delta^{13} \mathrm{C}$ measured or estimated & Estimated & measured & Measured & Missing & Total \\
\hline Number of outlier laboratories & 9 & 3 & 19 & 8 & $\mathbf{3 9}$ \\
All laboratories & 10 & 5 & 65 & 12 & $\mathbf{9 2}$ \\
\hline
\end{tabular}

Table 3.30 shows the types of background and modern standard materials used by laboratories with outliers and all laboratories. From this table, we can see that benzene was a far more commonly used background material in the outlier group (38\% of the time) than overall (21\%). This was also the case with the modern standards, where 6 out of the 7 laboratories using benzene were in the outlier group. It should be noted that the types of benzene used varied from laboratory to laboratory, unlike the other modern standards. 
Table 3.30 Types and numbers of laboratories using backgrounds and modern standards

\begin{tabular}{|c|c|c|c|c|c|}
\hline \multicolumn{3}{|c|}{ Background material } & \multicolumn{3}{|c|}{ Modern standard material } \\
\hline Category & Outlier laboratories & All & Category & Outlier laboratories & All \\
\hline Benzene & 15 & 19 & ANU Sucrose & 3 & 8 \\
\hline $\mathrm{CO}_{2}$ & 1 & 3 & Benzene & 6 & 7 \\
\hline Coal & 9 & 17 & NBS OXI & 6 & 21 \\
\hline Graphite & 1 & 4 & NBS OXII & 17 & 32 \\
\hline Marble & 2 & 6 & NBS OXI/OXII & 0 & 5 \\
\hline Natural Gas & 1 & 3 & 1 NBS \& 1 other & 3 & 3 \\
\hline Others & 4 & 10 & Other & 2 & 7 \\
\hline More than 1 & 1 & 13 & Missing & 2 & 9 \\
\hline Missing & 5 & 17 & Total & 39 & 92 \\
\hline Total & 39 & 92 & & & \\
\hline
\end{tabular}

\subsubsection{Conclusions}

A total of 122 observations out of 1056 (i.e., slightly over 10\%) were identified as anomalous (i.e., outliers). From the statistical definition of an outlier, around $5 \%$ of the results would have been expected to have been classed as outliers. Thus, approximately twice as many outliers were identified as would be expected if they were occurring purely by chance. Of the 122 outliers, $87 \%$ came from LSC laboratories. The distribution of outliers was uniform over the 10 samples; thus, no single sample contributed the majority of the outliers. Thirty-nine laboratories $(42 \%)$ had at least 1 result classed as an outlier. Of the 39 , almost $60 \%$ (23) of these had more than 1 of their results thus classed, and over one-fifth (9) had 5 or more such results.

Table 3.31 Operational information concerning laboratories with at least 1 outlier

\begin{tabular}{cllll}
\hline Lab nr & $\begin{array}{l}\delta^{13} \text { C measured }(\mathrm{M}) \\
\text { or estimated }(\mathrm{E})\end{array}$ & Background material & $\begin{array}{l}\text { Modern standard } \\
\text { material }\end{array}$ & $\begin{array}{l}\text { Nr of outlier } \\
\text { results }\end{array}$ \\
\hline 5 & E & IAEA C1 & NBS OXI & 7 \\
10 & - & Benzene & Benzene & 6 \\
11 & $\mathrm{M}$ & Anthracite & OXII / ANU & 4 \\
13 & $\mathrm{M}$ & Benzene & NBS OXII & 3 \\
15 & $\mathrm{M}$ & Anthracite & NBS OXII & 1 \\
16 & - & - & Benzene & 6 \\
17 & E & - & NBS OXI & 1 \\
18 & $\mathrm{M}(\mathrm{E} \& \mathrm{M})$ & Anthracite & NBS OXI & 1 \\
19 & $\mathrm{E}(\mathrm{E} \& \mathrm{M})$ & Methanol & NBS OXII & 1 \\
21 & $\mathrm{E}$ & Benzene & Benzene & 2 \\
23 & $\mathrm{M}$ & Anthracite & NBS OXII & 2 \\
26 & - & - & NBS OXII & 2 \\
28 & - & - & Benzene & 1 \\
30 & $\mathrm{M}$ & Benzene & ANU Sucrose & 1 \\
31 & $\mathrm{M}$ & TIRI-G CO & NBS OXII & 1 \\
32 & $\mathrm{M}$ & Marble & NBS OXII & 5 \\
39 & $\mathrm{M}$ & Benzene & Benzene & 2 \\
42 & $\mathrm{E}$ & Benzene & ANU Sucrose & 3 \\
43 & $\mathrm{M}$ & Anthracite & NBS OXII & 4 \\
44 & $\mathrm{M}$ & Graphite & &
\end{tabular}


Table 3.31 Operational information concerning laboratories with at least 1 outlier (Continued)

\begin{tabular}{lllll}
\hline Lab nr & $\begin{array}{l}\delta^{13} \text { C measured (M) } \\
\text { or estimated (E) }\end{array}$ & Background material & $\begin{array}{l}\text { Modern standard } \\
\text { material }\end{array}$ & $\begin{array}{l}\text { Nr of outlier } \\
\text { results }\end{array}$ \\
\hline 53 & $\mathrm{E}$ & Marble & ANU Sucrose & 9 \\
56 & $\mathrm{M}$ & Anthracite & NBS OXII & 2 \\
57 & $\mathrm{E}$ & Natural Gas & OXII / C3 & 1 \\
59 & $\mathrm{M}$ & Anthracite & NBS OXII & 1 \\
63 & $\mathrm{E}$ & Benzene & NBS OXII & 2 \\
66 & $\mathrm{M}$ & Limestone & NBS OXI & 1 \\
67 & $\mathrm{E}$ & Benzene & GIN & 3 \\
68 & $\mathrm{M}(\mathrm{E} \& \mathrm{M})$ & Benzene & NBS OXII & 1 \\
59 & $\mathrm{M}$ & Benzene & NBS OXII & 7 \\
70 & - & IAEA C4 & NBS OXI & 11 \\
71 & - & Benzene & Other & 3 \\
75 & - & Benzene & Other & 1 \\
76 & $\mathrm{M}$ & Benzene & Other & 1 \\
78 & - & - & - & 9 \\
80 & $\mathrm{M}$ & Benzene & NBS OXI & 1 \\
81 & $\mathrm{E}$ & Anthracite & NBS OXII & 4 \\
89 & $\mathrm{M}$ & Benz/Anthracite & NBS OXII & 1 \\
90 & $\mathrm{M}$ & Anthracite & NBS OXII & 4 \\
92 & $\mathrm{M}$ & Benzene & NBS OXII & 1 \\
\hline
\end{tabular}

Clearly, a relatively small number of laboratories (14\%) generated more than $60 \%$ of the outlying observations. The majority of these laboratories use liquid scintillation techniques (including direct absorption). However, it should be noted that there remains a substantial number of liquid scintillation laboratories with none or only 1 outlier.

Further analysis indicated that the presence of outliers was linked to the modern standard used, with some laboratories having no access to the primary standards of NIST OxI and OxII. 